\title{
TRANSFER OF R FACTORS FROM ESCHERICHIA COLI TO SALMONELLAS IN THE RUMEN OF SHEEP
}

\author{
M. G. SMITH \\ CSIRO Division of Food Research, Meat Research Laboratory, P.O. Box 12, \\ Cannon Hill, Queensland 4170, Australia
}

SUBSTANTIAL transfer of $\mathrm{R}$ factors was found to occur in vivo between strains of Escherichia coli inoculated into the rumen of sheep provided the animals were deprived of food for 24-48 h (Smith, 1975). No antibiotic treatment was necessary. Negligible transfer occurred without starvation even when large numbers of donor and recipient organisms (c. $10^{10}$ cells of each) were inoculated into the rumen. The present investigations were undertaken to determine whether $\mathrm{R}$ factors could be transferred under similar conditions from $E$. coli to pathogenic salmonellas.

\section{MATERIALS AND METHODS}

Bacteriological techniques. Strains of $E$. coli originally isolated from sheep and into which the same $\mathrm{R}$ factor (conferring resistance to streptomycin $25 \mu \mathrm{g}$ per $\mathrm{ml}$ and sulphadimidine $500 \mu \mathrm{g}$ per $\mathrm{ml}$ ) had been transferred, were tested in vitro for their ability to transfer the $\mathbf{R}$ factor to a series of salmonella cultures. Two combinations were chosen, donor strain D1 of $E$. coli with a strain of Salmonella lomita and donor strain D2 of E. coli with a strain of $S$. typhimurium. When c. $10^{6}$ cells each of the donor and prospective recipient strains were inoculated into nutrient broth (Oxoid) and incubated at $37^{\circ} \mathrm{C}$ for $24 \mathrm{~h}, 1-5 \%$ of the final number of cells were resistant salmonellas into which the $\mathrm{R}$ factor had been transferred.

Coliform organisms were counted on MacConkey Agar (Oxoid). The donor strains of E. coli were counted on this medium to which streptomycin $25 \mu \mathrm{g}$ per $\mathrm{ml}$ and sulphadimidine $500 \mu \mathrm{g}$ per $\mathrm{ml}$ had been added. Brilliant Green Agar (Oxoid) containing sulphadiazine (May \& Baker) $80 \mu \mathrm{g}$ per ml was used to determine total salmonellas. Resistant salmonella colonies, containing the $\mathrm{R}$ factor, were counted on this medium without sulphadiazine but containing the other antibiotics. All bacterial counts were performed by surface inoculation of agar plates from which excess surface moisture had been removed just before use by drying with the lid partially removed at $37^{\circ} \mathrm{C}$ for $30 \mathrm{~min}$.

Care of sheep, administration of inocula, and collection of samples. Six Merino wethers 3-4 years old were tethered in isolation cages and fed $1 \mathrm{~kg}$ of lucerne chaff per day. No antibiotics were administered in any form during the experiments and, as far as could be ascertained, none of the animals had been exposed to streptomycin or sulphadimidine. A pair of animals was used for each of the three feeding schedules and each animal was used once. Each combination of donor strain of $E$. coli and prospective recipient strain of salmonella was inoculated into a different animal to duplicate each type of experiment.

Techniques for administering inocula to the experimental animals and collecting rumen and faecal samples have been described previously (Smith, 1975). The bacterial cultures were grown in nutrient broth (Oxoid) at $37^{\circ} \mathrm{C}$ for $24 \mathrm{~h}$. A sterile sampling device was passed down the oesophagus into the rumen of each animal and the suspension of bacterial cells

Received 3 Feb. 1976; revised version accepted 1 June 1976.

J. MED. MICROBIOL.-VOL. 10 (1977) 
was washed through with $100 \mathrm{ml}$ of sterile $0 \cdot 1 \%(\mathrm{w} / \mathrm{v})$ peptone water. Separate sterile sampling devices were used to introduce the donor $E$. coli or recipient salmonellas into the rumen of each animal to ensure that no transfer occurred during inoculation. A sterile sampling device was used to withdraw c. $30 \mathrm{ml}$ of liquor from the rumen after the required time intervals and this was transferred to a sterile, capped jar. To minimise the transfer of $\mathbf{R}$ factors in the rumen liquor after it was withdrawn, each sample was spread within $10 \mathrm{~min}$. on the various selective agar media to determine the numbers of resistant coliform organisms, prospective salmonella recipients and resistant salmonella organisms present.

Freshly voided faecal samples were collected in a sterile plastic bag $(30 \times 46 \mathrm{~cm})$ clipped to the wool on the hindquarters of each animal. A suspension of $10 \mathrm{~g}$ of faeces in $90 \mathrm{ml}$ of $0.1 \%$ peptone water was made with a Sunbeam blender and examined within $5 \mathrm{~min}$. of preparation by plating on to the various selective media to minimise the transfer of $\mathrm{R}$ factors in the suspension.

Great care was taken to prevent the spread of salmonella organisms during the experiments. All faecal material was collected in plastic bags clipped to the wool on the hindquarters of the sheep and, after removing a small amount of faeces for bacterial counts, the remainder was autoclaved; the excess rumen fluid and faecal blends were treated with water at $75^{\circ} \mathrm{C}$; discarded agar plates and dilution tubes were steamed for at least $2 \mathrm{~h}$; and pipettes were placed in $0.1 \%(\mathrm{w} / \mathrm{v})$ aqueous alkyldimethylbenzylammonium chloride (Sterling Pharmaceuticals Pty Ltd, Sydney) immediately after use. After each experiment, the isolation cages were doused in hot water $\left(c .80^{\circ} \mathrm{C}\right)$ and scrubbed with an aqueous solution containing 200 parts per million of available chlorine ("Dairy Chlor ", Campbell Bros Pty Ltd, Brisbane).

\section{RESULTS}

\section{Inoculation followed by normal feeding}

Two animals maintained on a normal diet (1 kg of lucerne chaff per day) eliminated large numbers (c. $5 \times 10^{8}$ cells) of the inoculated donor strains of $E$. coli and the prospective recipient strains of salmonellas from the rumen within 2-3 days and from the faeces within 5-6 days. No resistant salmonellas were detected, indicating that negligible transfer of the $\mathrm{R}$ factor had occurred under these conditions. Both combinations of E. coli and salmonella organisms gave similar results.

\section{Inoculation followed by normal feeding and then starvation}

Another two animals similarly given $c .5 \times 10^{8}$ cells of both donor strains of $E$. coli and prospective recipient strains of salmonellas were fed for the first $24 \mathrm{~h}$ after inoculation and then starved for a further $30 \mathrm{~h}$. Each combination of E. coli and salmonella organisms gave similar results, and only those obtained with the animal given donor strain D2 and S. typhimurium are shown (fig. 1). While the animals were allowed to ingest food (for the first $24 \mathrm{~h}$ ) and for 6-8 $\mathrm{h}$ afterwards, the inoculated organisms decreased steadily in the rumen to reach small numbers (1-5 organisms per $\mathrm{ml}$ of rumen fluid). After $32 \mathrm{~h}$, both the donor strain $E$. coli and the salmonella organisms began to multiply rapidly. When the animal had been without food for $24 \mathrm{~h}$, antibioticresistant salmonellas were detected in the rumen, indicating that $\mathrm{R}$ factors had been transferred in vivo to the pathogen from the donor strain of $E$. coli. After the animal had fasted for $30 \mathrm{~h}$ it was re-fed. This was followed by another 


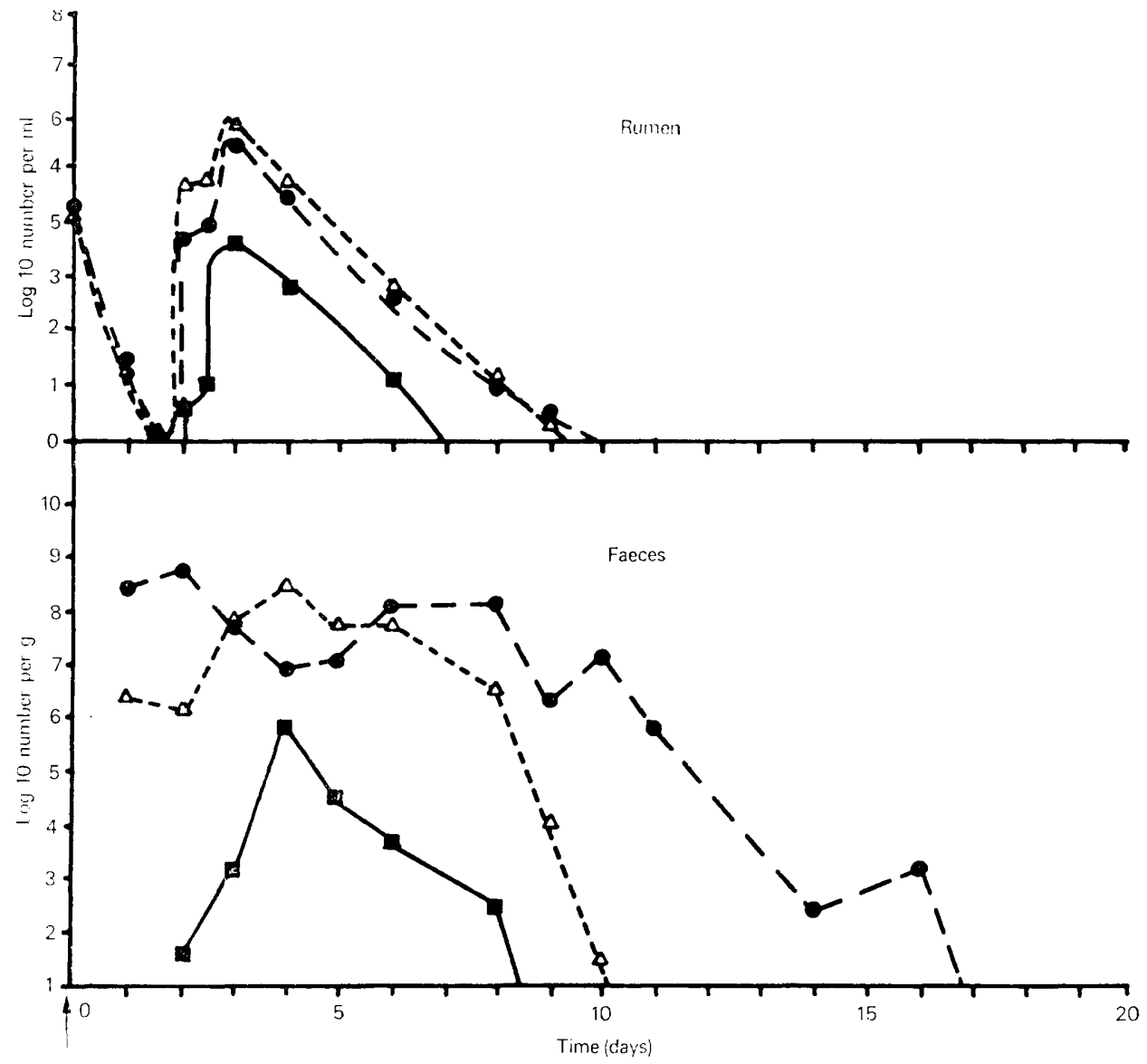

FIG. 1.-Viable counts in the rumen and faeces of $(\square)$ antibiotic-resistant salmonella organisms, (O) the donor strain of Escherichia coli, and $(\triangle)$ the recipient strain of Salmonella typhimurium at intervals after inoculation $(\uparrow)$ into the rumen of c. $5.6 \times 10^{8}$ of the donor strain and c. $4.4 \times 10^{8}$ of the recipient strain. The sheep was allowed to feed for $24 \mathrm{~h}$ after the inoculation, then starved for $30 \mathrm{~h}$, and then fed normally.

period of rapid growth of the inoculated organisms during which the numbers of antibiotic-resistant salmonellas increased; the latter increase was probably due to the growth of existing antibiotic-resistant organisms and the additional transfer of $\mathrm{R}$ factors to recipient salmonellas. The animals continued to feed, and all three types of organism declined in the rumen and were no longer detectable after a further 7 days.

The donor strains of $E$. coli and salmonella organisms were present in the faeces $24 \mathrm{~h}$ after the inoculum had been administered (see fig. 1). Antibioticresistant salmonellas containing $R$ factors were first detected in the faeces $24 \mathrm{~h}$ after the animal was deprived of food, i.e., $48 \mathrm{~h}$ after inoculation. As the number of each organism decreased in the rumen, there was a corresponding decrease in the faeces and none of the inoculated organisms was detectable 


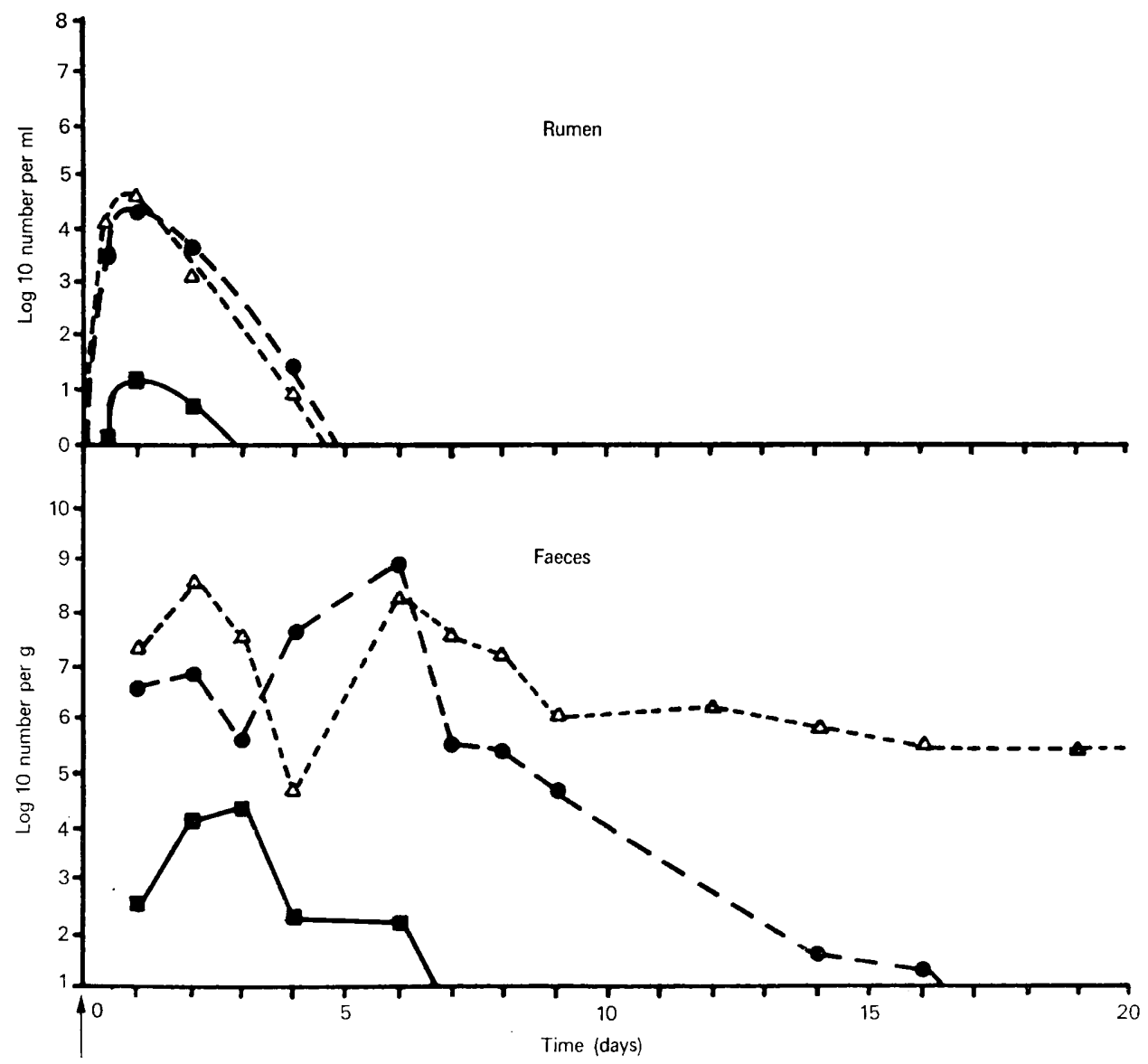

FIG. 2.-Viable counts in the rumen and faeces of $(\square)$ antibiotic-resistant salmonella organisms, (O) the donor strain of $E$. coli, and $(\triangle)$ the recipient strain of $S$. lomita at intervals after inoculation $(\uparrow)$ into the rumen of $c .2 \cdot 5 \times 10^{3}$ of the donor strain and c. $7 \cdot 8 \times 10^{3}$ of the recipient strain. The sheep had been starved for $48 \mathrm{~h}$ before the inoculation and then fed normally.

16 days later. Neither of the two animals used in this experiment showed any signs of illness.

\section{Inoculation into starved animals}

In a third type of experiment, small numbers of the donor strain of $E$. coli and prospective recipient salmonellas (c. $10^{2}-10^{4}$ cells of each) were introduced into the rumen of sheep that had been starved for $48 \mathrm{~h}$. Just before inoculation, samples of the rumen fluid were withdrawn and the numbers of resident coliform bacteria enumerated. In one animal (fig. 2) there was one coliform organism per $\mathrm{ml}$, and in the other (fig. 3) $2.4 \times 10$ coliform organisms per ml were present. Further samples were taken $30 \mathrm{~min}$. after inoculation. Approximately the same numbers of resident coliform bacteria were present but, in both cases, the numbers of inoculated donor and recipient organisms had been reduced to less than one organism per $\mathrm{ml}$ by the volume of fluid in the rumen. 


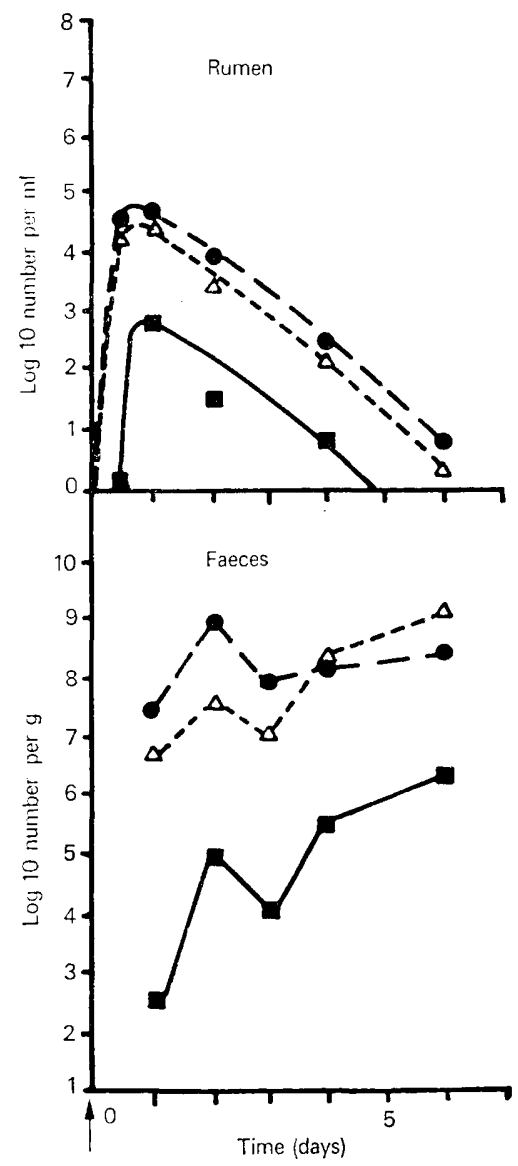

FIG. 3.-Viable counts in the rumen and faeces of $(\square)$ antibiotic-resistant salmonella organisms, (O) the donor strain of $E$. coli, and $(\triangle)$ the recipient strain of $S$. typhimurium at intervals after inoculation $(\uparrow)$ into the rumen of $c .5 .5 \times 10^{2}$ of the donor strain and $c .4 .6 \times 10^{2}$ of the recipient strain. The sheep had been starved for $48 \mathrm{~h}$ before the inoculation and then fed normally; it died on the 6 th day after the inoculation.

The animals were fed immediately after the second sample had been taken. The inoculated organisms soon began to multiply within the rumen, and some $7 \mathrm{~h}$ later antibiotic-resistant salmonellas were detected, indicating that transfer of the $\mathrm{R}$ factor had occurred. The donor strains of $E$. coli, prospective recipient salmonellas, and resistant salmonella cells reached maximum numbers after about $10 \mathrm{~h}$. The animals continued to eat freely, and the numbers of each organism in the rumen then began to decline.

The donor strains of $E$. coli, prospective recipient salmonellas, and resistant salmonellas, were detected in the faeces $24 \mathrm{~h}$ after inoculation. In one animal (fig. 2), which had been given the donor strain D1 and S. lomita, the resistant salmonellas could not be detected in the faeces after 5 days and strain D1 disappeared after 16 days. However, the prospective recipient $S$. lomita appeared to colonise the gastro-intestinal tract and was excreted continuously 
(105-106 cells per $g$ of faeces) for 3 weeks, after which the animal was destroyed to prevent possible cross-contamination.

The second animal (fig. 3), which had been given $4.4 \times 10^{2} S$. typhimurium, appeared normal until 5 days after inoculation, when it began to show signs of distress and loss of appetite. Its condition worsened rapidly and it died on the 6th day with typical signs of ovine salmonellosis (Seddon, 1953). The faeces were yellow and contained large quantities of mucoid material, and c. $10^{9} \mathrm{~S}$. typhimurium per g were isolated. As the numbers of $S$. typhimurium increased in the faeces during the 6 days of the experiment, the numbers of antibiotic-resistant salmonellas containing the $\mathrm{R}$ factor also increased to reach more than $10^{6}$ per $\mathrm{g}$ of faecal material. The numbers of salmonella cells, with and without the $\mathrm{R}$ factor, increased in the lower intestinal tract during the experiment but decreased in the rumen.

\section{Discussion}

It was previously shown (Smith, 1975) that, under certain conditions, and in the absence of antibiotic treatment, $R$ factors could be transferred readily in vivo between strains of $E$. coli inoculated into the rumen of sheep. The results of the present investigations show that, under the same conditions, $R$ factors are transferred from donor strains of $E$. coli to recipient salmonella organisms. Transfer could not be detected in animals maintained on a full diet, and large numbers of inoculated organisms (c. $10^{8}$ cells) disappeared within a few days. However, starvation for less than $48 \mathrm{~h}$ altered the ruminal environment so that, for about $10 \mathrm{~h}$ after the host animal was re-fed, it no longer exerted an inhibitory effect on the growth of inoculated $E$. coli or salmonellas. A similar effect was found previously in sheep (Grau, Brownlie and Smith, 1969) and in cattle (Brownlie and Grau, 1967). The inoculated $E$. coli and prospective salmonella recipients were then able to multiply, reaching large enough numbers for the $\mathrm{R}$ factor to be transferred. No antibiotics were administered in any form during these experiments, and it seems probable that other plasmids could be transferred in vivo under similar conditions.

One animal, to which $c .8 \times 10^{3} \mathrm{~S}$. lomita-less than one cell per $\mathrm{ml}$ of rumen fluid-had been given after starvation for $48 \mathrm{~h}$, became a carrier of this organism, but at no time did it show any symptoms of disease. Another animal, given after $48 \mathrm{~h}$ starvation $c .4 \times 10^{2}$ cells of $S$. typhimurium-less than one organism per $\mathrm{ml}$ of rumen fluid-after starvation for $48 \mathrm{~h}$, developed typical salmonellosis (Seddon, 1953) and died 6 days later. The onset of the disease, on the 5th day, was so acute that the animal died before veterinary help could be obtained. At the time of death there were large numbers of salmonellas (c. $10^{9}$ cells per $\mathrm{g}$ ) in the faeces and the number of these pathogens containing the $\mathbf{R}$ factor was increasing. This illustrates a potential problem associated with treatment of animals, and perhaps human subjects, when $\mathbf{R}$ factors are present. If this animal had been treated with either streptomycin or a sulphonamide (Blood and Henderson, 1963) after clinical signs had appeared, the 
number of antibiotic-sensitive salmonella cells might have been reduced; however, large numbers of antibiotic-resistant salmonellas were already present (c. $10^{6}$ cells per $\mathrm{g}$ of faecal material), so that treatment might have had little effect on the course of the disease.

Various species of animals are used to determine the pathogenicity of disease-causing organisms. Such animals are maintained under excellent conditions, are fed well and are in good health. Factors such as the virulence determinants of the infecting organism and the innate resistance of the host animal are of major importance in microbial pathogenicity, and the results obtained in the present experiments indicate that salmonellas may exhibit enhanced pathogenicity if the test animal is starved before challenge. Other situations such as fright, transient illness or changes in diet may induce stress and may also have an important influence on the development of an infection.

\section{SUMMARY}

Adult sheep were given into the rumen $c .10^{8}$ cells each of donor strains of $E$. coli containing an $\mathrm{R}$ factor and prospective salmonella-recipient organisms and were maintained on a diet of lucerne chaff; the animals excreted the organisms, remained healthy, and no transfer of the $\mathrm{R}$ factor was detected. When the animals were starved for $48 \mathrm{~h}$ before inoculation, the ruminal environment was altered so that, on resumption of feeding, small numbers (c. $10^{2}-10^{4}$ cells-less than one cell per $\mathrm{ml}$ of rumen fluid) of the introduced organisms were able to multiply and reach sufficient numbers for the transfer of $\mathrm{R}$ factors to occur within the rumen. One animal, given $7 \cdot 8 \times 10^{3}$ cells of recipient $S$. lomita after starvation for $48 \mathrm{~h}$, became a carrier of this organism. A second animal, given $4.4 \times 10^{2}$ cells of $S$. typhimurium after starvation for $48 \mathrm{~h}$, developed acute, fatal salmonellosis 5 days later; at the time of death, large numbers of salmonella organisms $\left(c .10^{9}\right.$ cells per $\left.\mathrm{g}\right)$ were present in the faeces; these included many (c. $10^{6}$ cells per $\mathrm{g}$ ) that had received the $\mathrm{R}$ factor by transfer in vivo. These results indicate that short periods of starvation may enhance the transfer of $\mathrm{R}$ factors and possibly other plasmids between suitable micro-organisms in vivo, and may increase the susceptibility of animals to pathogenic micro-organisms.

This work was supported in part by funds from the Australian Meat Research Committee.

\section{REFERENCES}

Blood, D. C. ANd Henderson, J. A. 1963. Veterinary medicine, 2nd ed., London, p. 469.

Brownlie, L. E. AND GraU, F. H. 1967. Effect of food intake on growth and survival of salmonellas and Escherichia coli in the bovine rumen. J. gen. Microbiol., 46, 125.

GraU, F. H., Brownlie, L. E. AND Smith, M. G. 1969. Effects of food intake on numbers of salmonellae and Escherichia coli in the rumen and faeces of sheep. J. appl. Bact., 32, 112.

Seddon, H. R. 1953. Diseases of domestic animals in Australia, pt. 5, vol. 1, Bacterial diseases, p. 278 (Service Publ. no. 9, Div. Vet. Hyg., Dept. Hlth, Canberra, Australia, 2600).

SMITH, M. G. 1975. In vivo transfer of R factors between Escherichia coli strains inoculated into the rumen of sheep. J. Hyg., Camb., 75, 363. 